\title{
Another perspective on the age and origin of the Berelyokh mammoth site-Comment to the paper published by Lozhkin and Anderson, Quaternary Research 89 (2018), 459-477
}

\author{
Vladimir V. Pitulko ${ }^{\mathrm{a} *}$, Elena Y. Pavlova ${ }^{\mathrm{b}}$, Aleksandr E. Basilyan ${ }^{\mathrm{c}}$, Pavel A. Nikolskiy ${ }^{\mathrm{c}}$ \\ ${ }^{a}$ Institute for the History of Material Culture, Russian Academy of Science, St. Petersburg, Russia \\ ${ }^{\mathrm{b}}$ Arctic and Antarctic Research Institute, St. Petersburg, Russia \\ ${ }^{\mathrm{c}}$ Geological Institute, Russian Academy of Science, Moscow, Russia \\ (Received July 2, 2018; ACCEPTED July 11, 2018)
}

Keywords: Berelekh; Mammoth accumulation; Chronometry; Beringia; Pleistocene environment; Stone Age archaeology

The work reviewed (Lozhkin and Anderson, 2018) concerns the concept of the mass demise of mammoth herds in a hypothetical thermokarst lake resulting in mass bone accumulations. Our research concerning Berelekh (Nikolskiy et al., 2010, 2011; Pitulko, 2011; Pitulko et al., 2014) is quoted comprehensively; however, the work contests, without evidence, our conclusions (Pitulko et al., 2014), which are rooted in geologic facts and deposit chronometry of the Berelekh geoarchaeological complex (BGC hereafter) (Fig. 1). We have both technical and scientific questions for its authors.

\section{TECHNICAL QUESTIONS}

The article lacks either information on geomorphology, section documentation or description, or a simple schematic explaining the spatial and hypsometric correlation of the section and the lithologic sequence from a certain location, presented in the article (Table 1 in Lozhkin and Anderson, 2018). Moreover, the description, as well as the hypsometric scale (Fig. 2 in Lozhkin and Anderson, 2018), violates the geologic description standard (bottom to top). Finally, their figure 2, showing the hypothetical reconstruction, directly follows the map and opens a series of images, which present factual materials, its position lending it some undeserved legitimacy.

This is absolutely unacceptable because such reconstruction should logically conclude the series and reflect the real geomorphology of the location, for which events are reconstructed; it should not contain comprehensive hypsometry, so as not to appear to be true. These issues should have been resolved during the peer review.

*Corresponding author at: Institute for the History of Material Culture, Russian Academy of Science, St. Petersburg, Russia. E-mail address: pitulkov@gmail.com (V.V. Pitulko).

\section{GEOLOGIC FACTS}

The article contains no geologic facts capable of refuting conclusions regarding the timing and mechanism of the Berelekh mammoth boneyard formation, presented in Pitulko et al. (2014) based on the detailed study of the BGC geology in 2004 and 2009. We (1) identified the basic section elements; (2) identified the spatial interconnection among objects; (3) compiled the geomorphological map; and (4) located, described, and radiocarbon-dated certain section elements (facies of various geneses) and identified layer contacts. We comprehensively studied geocryological characteristics of the deposits, used to evaluate the history of cryogenic facies (French and Shur, 2010). We established (Pitulko et al., 2014) that the deposits, containing the bonebearing lens and the archaeological cultural horizon, compose the second terrace above the floodplain and are adjacent to the alluvium of the third terrace above the floodplain; the mammoth bone accumulation had belonged to the part of the ancient river bed as it was becoming an oxbow.

In the BGC section, there is no geologic or cryostratigraphic evidence to support the idea (Lozhkin and Anderson, 2018) of a thermokarst trap lake at the location, where a group of mammoths could have perished. A characteristic feature of such formations is a thick horizon of melt sediments with a characteristic massive cryotexture (lacustrine talik), cutting through lower deposits and syncryogenic frozen structures, overlapped by lacustrine deposits with gradual increase of the organic component, which are covered by autochthonous peat. The lack of this deposit at BGC means there was no lake.

The lithologic sequence (not a section, but only a deposit sequence described at some location), presented by Lozhkin and Anderson, corresponds to the upper part of the second terrace revealed in our exposed sections (Fig. 1). It was probably observed in the profile of one of field test sites in Vereshchagin's erosion areas along the bank of the paleochannel, where mammoth remains were buried. 


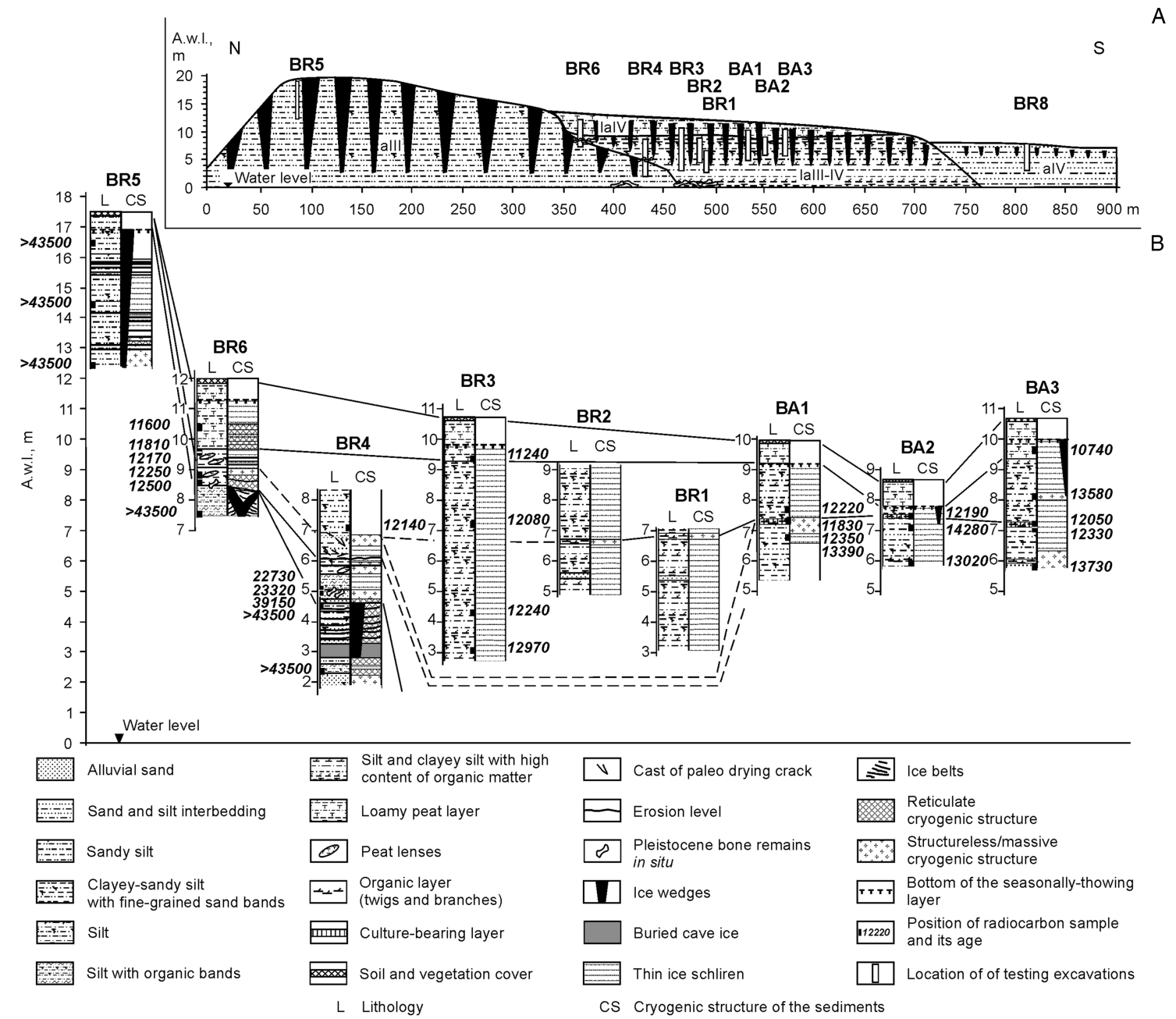


For some reason, the researchers use this sequence to dispute the results of our work. We note that attempting to explain deposit genesis based on lithologic characteristics and spore-pollen composition is, geologically speaking, not credible.

The pattern presented by Lozhkin and Anderson in their figure 2 is a hypothetical reconstruction with no reliably established geologic facts. This is obvious from a simple comparison of this image with the facts we presented (Fig. 1).

Nevertheless, manifestations of lacustrine thermokarst in the later postglacial period and Holocene in the northern Yana-Indighirka lowland, where they are an important landscape-forming factor, are widely known (Kaplina, 2009). These processes began around 13,000-12,000 yr ago; however, at that time the relative number of mammoths in Arctic Siberia grew rapidly to the maximum we have established for Marine Oxygen Isotope Stages 3 and 2 (Nikolskiy et al., 2011).

\section{CHRONOMETRY OF THE BERELEKH BONE-BEARING HORIZON}

Radiocarbon-date manipulations (using an abbreviated sample) and their interpretations (Lozhkin and Anderson, 2018) remain mysterious. The Yana mammoth "graveyard" (YMAM) had been formed for about 5000-6000 yr, 29,000 through 24,000 ${ }^{14} \mathrm{C}$ yr BP, without mass mortality episodes (there are no close date clusters). Its accumulation is associated with anthropogenic activities in the form of successive hunting episodes, 1-2 animals killed every year (Basilyan et al., 2011; Pitulko et al., 2015). The reconstructed number is at least 100 animals, possibly as high as 300 or more.

The Berelekh boneyard formed around $13,700-11,800{ }^{14} \mathrm{C}$ yr BP, with accumulation peaks at $12,600-12,200{ }^{14} \mathrm{C}$ yr BP and $12,000-11,800{ }^{14} \mathrm{C}$ yr BP, which correlate with the Bølling-Allerød warming (Pitulko et al., 2014). Such oscillations indeed have not been suggested for western Beringia, nor do we distinguish them, as it seemed to Lozhkin and Anderson. We simply noted the timing coincidence of the peaks of mammoth remains accumulation and these oscillations.

The total time of mammoth remains accumulation at Berelekh is around $2000 \mathrm{yr}$ (Pitulko et al., 2014), resulting in the deposit of remains of 140-200 mammoths (Vereschagin, 1977). This number is only impressive if a single mass demise event took place; otherwise, simple division yields the average accumulation rate of 1 mammoth every $10 \mathrm{yr}$, similar to the YMAM rate of accumulation (Pitulko et al., 2015), though in both cases accelerated accumulation periods are observed. At the same time, smaller mammoth sites known in the area, whose geological age is close to the BGC one, e.g. Achchaghyi-Allaikha (Nikolskiy et al., 2010), IlynSyalakh (Pitulko et al., 2013), Nikita Lake and Urez 22 (Pitulko et al., 2016) took a much shorter time to accumulate. Notably, all of them have clear indication of human involvement in the site formation process.
Mass demise events (single or repeated), advocated by Lozhkin and Anderson, would have left numerous articulated skeletons or their main parts. Vereshchagin (1977) describes nothing of the kind. Those have not been found in YMAM either. However, in both cases there are skin fragments, mammoth hair, and bones with noticeably preserved tissues. Both at BGC and YMAM, concentrations of mammoth bones are associated with conditions of low-energy or stagnant water flow (a marsh or an oxbow). These conditions were an important element of the mammoth tusk processing technology practiced by the ancient population in the northern Yana-Indighirka lowland (Pitulko et al., 2015), which brings up the question of the degree of anthropogenic contribution to the formation of the Berelekh boneyard.

Thus, an alternative view on the timeframe, mechanism, and causes of the formation of the Berelekh mammoth remains accumulation has neither geologic nor chronometric evidence, and the construction as a whole lacks a factual basis. There had been conditions for lake thermokarst development in Arctic western Beringia 13,000 cal yr BP and later, but there is no direct link between this phenomenon and mammoth mortality at Berelekh. In other words, Lozhkin and Anderson's view of this question has no scientific perspective.

\section{ACKNOWLEDGMENTS}

The authors would like to thank the Editorial Board for the opportunity to present this response. We are also grateful to the Russian Science Foundation (Project No. 16-18-10265- RNF) for supporting our work.

\section{REFERENCES}

Basilyan, A.E., Anisimov, M.A., Nikolskiy, P.A., Pitulko, V.V., 2011. Woolly mammoth mass accumulation next to the Palaeolithic Yana RHS site, Arctic Siberia: its geology, age, and relation to past human activity. Journal of Archaeological Science 38, 2461-2474.

French, H., Shur, Y. 2010. The principles of cryostratigraphy. Earth-Science Reviews 101, 190-206.

Kaplina, T.N., 2009. Alas complex of North Yakutia. Earth's Cryosphere 13, 3-17.

Lozkin, A.V., Anderson, P.M., 2018. Another perspective on the age and origin of the Berelyokh mammoth site (northeast Siberia). Quaternary Research 89, 459-477.

Nikolskiy, P.A., Basilyan, A.E., Sulerzhitsky, L.D., Pitulko, V.V., 2010. Prelude to the extinction: revision of the AchchagyiAllaikha and Berelekh mass accumulations of mammoth. Quaternary International 219, 16-25.

Nikolskiy, P.A., Sulerzhitsky, L.D., Pitulko, V.V., 2011. Last straw versus Blitzkrieg overkill: climate-driven changes in the Arctic Siberia mammoth population and the Late Pleistocene extinction problem. Quaternary Science Reviews 30, 2309-2328.

Pitulko, V.V., 2011. The Berelekh quest: a review of forty years of research in the mammoth graveyard in northeast Siberia. Geoarchaeology 26, 5-32. 
Pitulko, V.V., Basilyan, A.E., Pavlova, E.Y., 2013. Mass accumulations of mammoth bones with traces of human activity (Ilin-Syalakh River, northern Yana-Indighirka lowland). [In Russian.] Transactions of the Institute for the History of Material Culture 8, 34-52.

Pitulko, V.V., Basilyan, A.E., Pavlova, E.Y., 2014. The Berelekh mammoth "graveyard": new chronological and stratigraphical data from the 2009 field season. Geoarchaeology 29, 277-299.

Pitulko, V.V., Pavlova, E.Y., Basilyan, A.E., 2016. Mass accumulations of mammoth (mammoth "graveyards") with indications of past human activity in the northern YanaIndighirka lowland, Arctic Siberia. Quaternary International 406, 202-217.

Pitulko, V.V., Pavlova, E.Y., Nikolskiy, P.A., 2015. Mammoth ivory technologies in the Upper Palaeolithic: a case study based on the materials from Yana RHS, northern YanaIndighirka lowland, Arctic Siberia. World Archaeology 47, 333-389.

Vereschagin, N.K., 1977. Berelekh mammoth "graveyard." [In Russian.] Proceedings of Zoological Institute 72, 5-50. 